\title{
Effectiveness of $0.2 \%$ sodium fluoride and $0.2 \%$ chlorhexidine gluconate mouthrinses accompanied tooth brushing on gingival health during orthodontic therapy: A comparative study
}

\author{
Tarik Y KHAMRCO * \\ Ali R AL-KHATIB ** \\ Ban S AL-MUKHTAR***
}

\begin{abstract}
This study was carried out to evaluate the action of $0.2 \%$ sodium fluoride ( $900 \mathrm{ppmF}$ ), and $0.2 \%$ chlorhexidine gluconate mouthrinses besides tooth brushing on plaque and gingival indices. To achieve this aim 45 patients undergoing fixed orthodontic therapy were divided into 3 equal groups randomly which were on tooth brushing only, tooth brushing with $0.2 \%$ sodium fluoride and tooth brushing with $0.2 \%$ chlorhexidine mouthrinses. The second group rinse with $10 \mathrm{ml}$ of sodium fluoride once weekly for 8 weeks, while the third group rinse with $10 \mathrm{ml}$ of chlorhexidine twice daily for the same period, the plaque and gingival indices were scored at base-line and then evaluated after 4 and 8 weeks. The present study revealed that the mean plaque index was significantly reduce $(\mathrm{p}<0.05)$ for the chlorhexidine and sodium fluoride patients in comparison with the first group throughout period of study. A similar trend was noted with gingival index as the lower values were recorded to the chlorhexidine groups, moreover, analysis of variance showed significant differences among groups and the chlorhexidine means were the mostly affected one. These results indicate that sodium fluoride could be use also for plaque and gingivitis control in addition to its anticariogenic action for patient undergoing orthodontic treatment.
\end{abstract}

Key Worls: Naf mouth rinse, chlorhexidine, dental plaque, gingivitis.

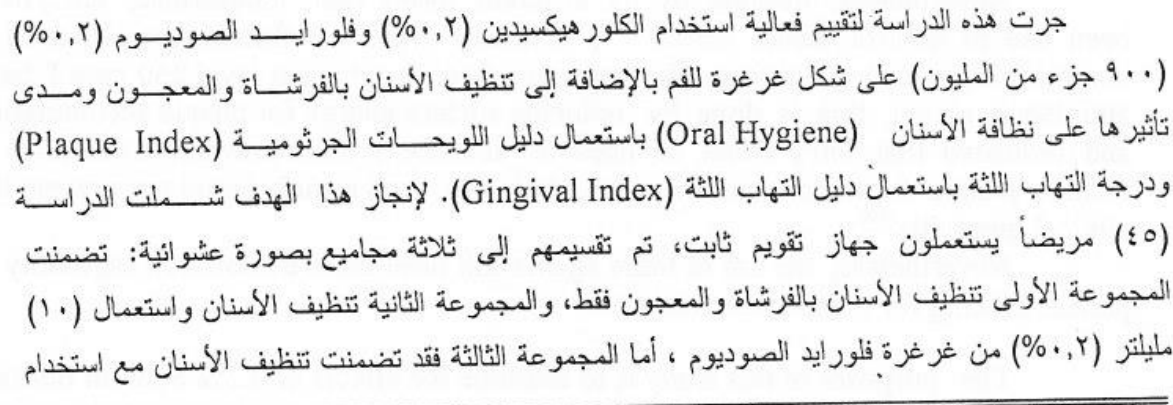

*Tarik Yousif KHAMRCO ; BDS, DDPH(RCS), MSc : Assistant Prof.

**Ali Rajeh AL-KHATIB; BDS, MSc : Assistant Lecturer.

***Ban Safar AL-MUKHTAR; BDS, MSc : Assistant Lecturer.

Department of Pedodontics, Orthodontics, \& Preventive Dentistry, College of Dentistry, University of Mosul, Mosul, IRAQ. 


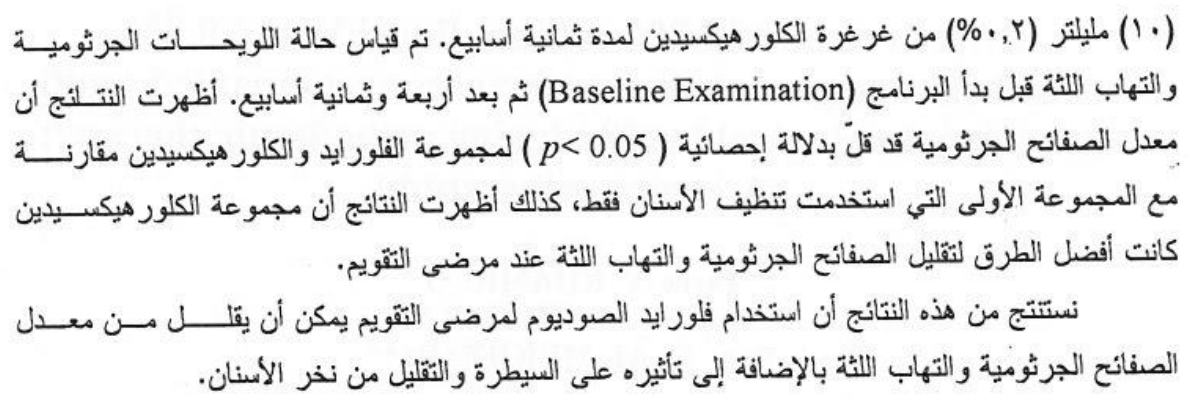

\section{INTRODUCTION}

One of most dramatic issues of orthodontic treatment is to rearrange teeth in such a manner that produce clinically correct dental relationship, also to remove areas of food stagnation, and maintain gingival regions in a form that promote healthy oral condition.

Throughout the orthodontic procedures and as a result of bands, brackets and wire placement, there will be an accumulation of food residues, which, in time cause periodontal, gingival problems and also dental caries ${ }^{(1)}$.

The mechanical cleaning of tooth surfaces can be accomplished in various forms, and tooth brushing is routinely advised to orthodontic patient, so as to minimize the previously mention hazards ${ }^{(2)}$. In spite of that, there is an increasing need for the chemical agents that could control plaque formation and subsequent gingivitis $^{(3)}$, and also to prevent dental caries formation ${ }^{(4)}$.

The use of chlorhexidine mouthrinse has been noticed since 1970, as rinsing with $0.2 \%$ chlorhexidine gluconate, twice daily is used to prevent plaque and gingivitis ${ }^{(5)}$. Other authors reported a similar results but all suggested that continued patient motivation regarding oral hygiene should be continue during orthodontic treatment to control gingival and periodontal problems $s^{(3,5-6)}$

Nevertheless, fluoride by its different forms (gel, mouthrinse, etc..) have been use to control dental caries ${ }^{(7-10)}$, a similar types of fluoride are also used to control plaque and gingivitis, like stannous fluoride which at level $250 \mathrm{ppm} F$ have antiplaque action, this is done by reducing surface energy for plaque accumulation and indicated that $\mathrm{SnF}_{2}$ could be used in absence of other preventive measures to control plaque formation but in twice daily use, such a study could not prevent the clinical gingivitis ${ }^{(10)}$

Nevertheless, the use of these agents still need more exploration especially in patient seeking for orthodontic treatment.

The purposes of this study is to examine the effects of $0.2 \%$ Sodium fluoride $(900 \mathrm{ppmF})$ and $0.2 \%$ chlorhexidine gluconate mouthrinses to control plaque and gingivitis, together with tooth brushing in orthodontic patients. 


\section{MATERIALS AND METHODS}

The sample of this study consisted of 45 patients who were receiving orthodontic treatment at Orthodontic Department of the College of Dentistry in Mosul University. All participants did not received any medications that have any oral side effects, their age was range between 11-18 years. All of them had a bilateral banded first molar and fully bonded dental arch except the extracted teeth for Orthodontic purposes.

First of all, patients received as dental prophylaxis, that included stain, plaque and calculus removal, after that they were randomize into 3 groups each of 15 patient, the first group used the tooth brushing only, the second group was on tooth brushing with $0.2 \%$ sodium fluoride* ( $900 \mathrm{ppm} \mathrm{F}$ ) mouthrinse weekly, while the third one was on tooth brushing with the chlorhexidine gluconate $(0.2 \%)$ twice daily, after a period of 14 days the baseline data were measured ; the first and second examinations were carried out 4 and 8 weeks after the baseline examination.

The following indices were used to asses the oral hygiene and gingival health of the patients:

1. Plaque index according to Silness and Löe $(1964)^{(11)}$.

2. Gingival index according to Löe $(1967)^{(12)}$

The plaque index was used to determine thè amount of plaque on tooth surfaces (mesiofacial, facial, distofacial and palatal or lingual surfaces) of six teeth (No. 3, 9, 13, 19, 25 and either 28 or 29) depending on which premolar was extracted for orthodontic purposes

The scores were recorded as a grades $(0,1,2,3)$ depending on the presence of plaque accumulation "1).

The gingival index was used to indicate the degree of inflammation of the marginal gingiva on the same surfaces of the same teeth as recorded for plaque index.

Then, all patients $(n=45)$ were received the same tooth brushing instructionsModified Bass technique, they were informed to brush their teeth twice daily, also a same tooth paste was prescribed for all patients. In accompanied to that, the secnnd group received a supplies of $0.2 \%$ Sodium fluoride solution of ( $900 \mathrm{ppm} \mathrm{F}$ ), they were instructed to use solution of $10 \mathrm{ml}$ sodium fluoride for 3 minutes, once weekly, before bed time, they were instructed not to take any food or drink after rinsing.

While the third group was instructed to rinse within $10 \mathrm{ml}$ of $0.2 \%$ chlorhexidine gluconate for 30 seconds, twice daily, after breakfast and before bedtime, also they were instructed not to take any food or drink after using of solution.

The statistical analysis of data included the following:

1) Mean and standard deviation for plaque and gingival indices.

2) The differences in plaque score and gingival health between baseline examination and the first and second examinations were tested statistically using student $\mathrm{t}-$ test.

3) Analysis of variance followed by Duncan's Multiple Range Test were used to determine the significant differences among the treatment groups.

The differences were considered significant when the probability was less than $5 \%$ level $(p<0.05)$

* Prepared by Dr. Tarik Y Khamrco in Dentistry College/ Mosul University. 


\section{RESULTS}

In this study, the IBM computer programmes were used in the analyses of the data, the paired t-test was used to do the analyses between groups, the results of this test showed that both plaque and gingival indices means did not differ at baseline for the involved groups as shown in table 1 and 2 respectively.

The results indicated that both the mean plaque and gingival in dices for the fluoridate and chlorhexidine groups were significantly reduced from baseline examination at 4 weeks and 8 weeks examinations, while the tooth brushing group show a slight, not significant increase for plaque and gingival indices at 8 weeks examination (Tables 1, 2).

Table (1): Comparison between mean values of plaque index for each of the study groups of different time intervals.

\begin{tabular}{|c|c|c|c|c|c|c|c|}
\hline \multirow{2}{*}{ (8) } & \multirow{2}{*}{ No. } & \multicolumn{2}{|c|}{ Bhasilin: } & \multicolumn{2}{|c|}{ 4. weeks } & \multicolumn{2}{|c|}{ 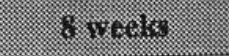 } \\
\hline & & vern: & -510 & yesin & -58 & $11 \mathrm{zan}$ & 1818 \\
\hline Tooth brushing & 15 & 1.03 & 0.62 & $1.05^{* *}$ & 0.45 & $1.09 * *$ & 0.51 \\
\hline $\begin{array}{l}\text { Tooth brushing + } \\
\text { Fluoride }\end{array}$ & 15 & 0.92 & 0.53 & $0.69^{* * *}$ & 0.43 & $0.66^{* * *}$ & 0.29 \\
\hline $\begin{array}{c}\text { Tooth brushing }+ \\
\text { CHX }\end{array}$ & 15 & 0.98 & 0.51 & $0.54^{* * *}$ & 0.29 & $0.27 * * *$ & 0.20 \\
\hline
\end{tabular}

* No significant difference at $p<0.05$ between the base line group.

** No significant difference at $p<0.05$ between intervals.

*** Significant difference at $\mathrm{p}<0.05$ between intervals.

Table (2): Comparison between mean values of gingival index for each of the study groups at different time intervals.

\begin{tabular}{|c|c|c|c|c|c|c|c|}
\hline \multirow{2}{*}{$(9.6010)$} & \multirow{2}{*}{ (1): } & \multicolumn{2}{|c|}{ 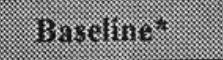 } & \multicolumn{2}{|c|}{  } & \multicolumn{2}{|c|}{$8 \cdot 1(1,61,1)$} \\
\hline & & 1):19:3: & -510 & 130. & $=810$ & Nisis: & $\sin$ \\
\hline Tooth brushing & 15 & 1.79 & 0.22 & $1.72 * *$ & 0.19 & $1.83 * *$ & 0.25 \\
\hline $\begin{array}{c}\text { Fluoride }+ \text { tooth } \\
\text { brushing }\end{array}$ & 15 & 1.64 & 0.33 & $1.54 * * *$ & 0.35 & $1.16 * * *$ & 0.39 \\
\hline $\begin{array}{l}\mathrm{CHX}+\text { tooth } \\
\text { brushing }\end{array}$ & 15 & 1.77 & 0.15 & $0.94 * * *$ & 0.12 & $0.58 * * *$ & 0.18 \\
\hline
\end{tabular}

* No significant difference at $p<0.05$ between the base line groups.

** No significant difference at $p<0.05$ between intervals.

*** Significant difference at $\mathrm{p}<0.05$ between intervals. 
The analysis of variance for both plaque and gingival indices at 8 weeks examination shows that the group with chlorhexidine is significantly better improved than fluoride and tooth brushing groups. Also, the fluoridate group reported a significant improvement than tooth brushing group for both indices (Table 3 ).

Table (3): Analysis of variance among study groups at last interval for plaque and gingival indices.

\begin{tabular}{|c|c|c|c|c|c|c|c|}
\hline \multirow[b]{2}{*}{ linition: } & \multicolumn{3}{|c|}{ i. } & \multicolumn{4}{|c|}{ 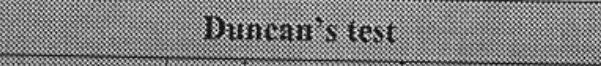 } \\
\hline & 10 & $\sqrt{3} \sin$ & litill & 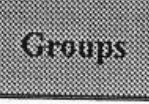 & 10 & 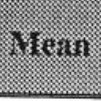 & 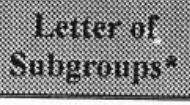 \\
\hline \multirow{3}{*}{ Plaque } & \multirow{3}{*}{45} & \multirow{3}{*}{17.434} & \multirow{3}{*}{0.05} & TB & 15 & 1.09 & A \\
\hline & & & & $\mathrm{TB}+\mathrm{F}$ & 15 & 0.66 & $\mathrm{~B}$ \\
\hline & & & & $\mathrm{TB}+\mathrm{CH}$ & 15 & 0.27 & $\mathrm{C}$ \\
\hline \multirow{3}{*}{ Gingival } & \multirow{3}{*}{45} & \multirow{3}{*}{66.677} & \multirow{3}{*}{0.05} & $\mathrm{~TB}$ & 15 & 1.83 & A \\
\hline & & & & $\mathrm{TB}+\mathrm{F}$ & 15 & 1.16 & B \\
\hline & & & & $\mathrm{TB}+\mathrm{CH}$ & 15 & 0.58 & $\mathrm{C}$ \\
\hline
\end{tabular}

* Subgroups with the same letter were not statistically significant

$\mathrm{TB}=$ Tooth brushing

$\mathrm{F}=$ Fluoride

$\mathrm{CH}=$ Chlorhexidine

\section{DISCUSSION}

It has been found that the gingival and periodontal problems will increase after placement of orthodontic appliances. Since attachment of such an appliance gives better opportunities for retention of dental plaque, that permits bacterial growth. Moreover, the orthodontic appliances will interfere with the process of brushing, mastication and salivary flow ${ }^{(3)}$.

In order to examine one of the preventive measure that could be use on orthodontic practice, the assessment of topical sodium fluoride and chlorhexidine gluconate mouthrinses with tooth brushing at short contact time were chosen.

It is an important to say that the study groups were chosen by random assignment, and they are evenly distributed as it has been demonstrated by baseline results, this point is of prime importance specially in the comparative study.

The clinical tria 1 reveals the favorable action of topical sodium fluoride and chlorhexidine gluconate mouthrinses as they were produce a significant reduction in plaque and gingival indices, these finding become more apparent after 8 weeks as the sodium fluoride and the chlorhexidine groups showed a reduced level of plaque and 
the marginal gingiva, this is similar to the findings of Brightman et al ${ }^{(3)}$. Anderson et $a l l^{(6)}$, in relation to chlorhexidine and with Vierrou et $a l^{(8)}$ in relation to sodium fluoride. It is important to say that the finding of this study are in different situation with some authors ${ }^{(13)}$. They found that only the mechanical cleaning was effective in preventing gingival inflammation as compared with $0.12 \%$ chlorhexidine and with those how indicated that the use of sodium fluoride be ineffective in control gingival problems ${ }^{(14-15)}$, the conflicting with those studies may be due to the difference in population or in chemicals concentration, patient co-operation with the investigators, and period of study.

The present study shows that chlorhexidine mouthrinse be with a highly significant reduction in plaque and gingival indices in comparison to that produced by sodium fluoride. These results were in agreement with other studies ${ }^{(16-17)}$. These may be due to large intervals between application time for the sodium fluoride because Svatun $e t a l .{ }^{(18)}$ found that the plaque - inhibiting effect of once daily $(0.2 \%)$ or $(0.3 \%)$ stannous fluoride mouthrinse was comparable to the once daily $(0.1 \%)$ chlorhexidine. In spite of that, the chlorhexidine group was shown some defect, like teeth discoloration mainly the composite restorations, in accompanied to a bitter taste sensation of the agent, for that reason the sodium fluoride mouthrinses appear to have an acceptable action on gingival health, this is besides it's well known as anticariogenic action ${ }^{(8)}$

\section{CONCLUSIONS AND RECOMMENDATIONS}

The short term application of sodium fluoride and chlorhexidine gluconate was proved to have a significant role in reduction of plaque formation and gingival inflammation. Chlorhexidine was appeared to be the more efficient one, but the additive anticariogenic action of sodium fluoride, and the short number of application times with less defects than chlorhexidine make it more preferable.

The follow up studies for the action of the sodium fluoride or the other types of topical fluoride in addition to increase the frequency of application is recommended to determine their action on the gingival health of orthodontic patients.

\section{REFERENCES}

1. Zachrisson BU, Zachrison S. Caries incidence and oral hygiene during orthodontic treatment. Scand J Dent Res. 1971; 79: 394-401.

2. Kilicogu H, Yildirim M, Polater H. Comparison of the effectiveness of two types of tooth brushers on the oral hygiene of patient undergoing Orthodontic treatment with fixed appliances. AJI-DO. 1997; 11: 591-594.

3. Brightman LJ, Terezhalmg GT, Greenwell H, Jacobs M, Enlow DH. The effect of a $0.12 \%$ chlorhexidine gluconate mouthrinse on orthodontic patient aged 11 through 17 with established gingivitis. AJO-DO. 1991; 100: 324-329.

4. Shrestha BM, Sheila A, Mundroff, Bibby BG. Enamel Dissolution: I. Effects of various agents and titanium tetrafluoride. J Dent Res. 1972; Nov-Dec: 1561-1573.

5. Löe H, Schiott CR. The effect of mouthrinses and topical application of chlorhexidine on the development of dental plaque and gingivitis in man. $J$ Periodont Res. 1970; 5: 79-83. 
6. Anderson GB, Bowden J, Morrison EC, Caffesse RG. Clinical effects of chlorhexidine mouthwashes on patients undergoing orthodontic treatment. AJODO. 1997; 111: 606-612.

7. Oostrwaol PJ, Mikx FH, Van den Brink ME, Renggli HH, Bactericidal concentration of chlorhexidine digluconate, amine fluoride gel and stannous fluoride gel for subgingival tested in serum at contact time. J Periodont Res. 1989; 24: 155-160.

8. Vierrou AM, Manwell MA, Zamek RL, Sachda Va RC, Tinaoff N. Control of Streptococcus mutans with topical fluoride in patients undergoing orthodontic treatment. J Am Dent Assoc, 1986; 113: 644-646.

9. Maltz M, Emilson CG. Susceptibility of oral bacteria to various fluoride salts. $J$ Dent Res. 1982; 61: 786-790.

10. Yonkell SL, Stoller NH, Green PA, Shern RJ. Clinical effects of using stannous fluoride mouthrinses during a five day study in the absence of oral hygiene. $J$ Periodont Res. 1982; 17: 374-379.

11. Silness P, Löe J. Periodontal disease in pregnancy. Acta Odontol Scand. 1964; 22 : 121-135.

12. Löe $\mathrm{H}$. The gingival index, the plaque index and the retention index systems. $J$ Periodont Res. 1967; 38: 38-44.

13. Caton JG, Blieden TM, Lowenguth RA. Lang NP,'Ruber K. Use of oral irrigators as a vehicle for the application of antimicrobial agents in chemical plaque control. J Clin Periodontol. 1993; 20: 172-178.

14. Tinanof N. Microbiology effect of $\mathrm{SnF}_{2}$ and sodium fluoride mouthrinses in subject with caries activity: results of one year. J Dent Res. 1983; 62: 907-911.

15. Tinanoff N, Gamosci DA. Microbiological, ultrastructural and spectrosccpic analyses for antitooth plaque properties of fluoride compound in vitro. Arch Oral Biol. 1980; 25: 531-543.

16. Hellden L, Camosci D, Hock J, Tinanoff N. Clinical study to compare the effect of stannous fluoride and chlorhexidine mouthrinses on plaque formation. J Clin Periodontol. 1981; 8: 12-16.

17. Abbas DK, Al-Safi F, Al-Zahid N. The relative effectiveness of stannous fluoride to chlorhexidine in the inhibition of dental plaque. Iraqi Dent J. 1989; 14: 40-48.

18. Svatun B, Gjermo P, Eriksen H, Rølla G. Comparison of the plaque inhibiting effect of stannous fluoride and chlorhexidine. Acta Odontol Scand. 1977; 35: 247250 . 